\title{
Riscos ocupacionais na legislação trabalhista brasileira: destaque para aqueles relativos à saúde e à voz do professor
}

\author{
Occupational risks in the Brazilian labor legislation: highlight \\ on those related to teacher's health and voice
}

Emilse Aparecida Merlin Servilha ${ }^{1}$, Rayana de Oliveira França Leal ${ }^{2}$, Mariene Terumi Umeoka Hidaka ${ }^{3}$

\begin{abstract}
RESUMO
Objetivo: Analisar a legislação a respeito de riscos ocupacionais, com destaque para aqueles relacionados à saúde e à voz do professor. Métodos: Trata-se de pesquisa bibliográfica, de caráter qualitativo, que considerou as políticas públicas sobre Saúde e Segurança no Trabalho. As Normas Regulamentadoras foram lidas e seus conteúdos analisados e organizados por categorias, com recorte para aqueles referentes ao ambiente escolar. Resultados: As 33 normas focalizam os fatores de risco, níveis de tolerância e controle para saúde e segurança no trabalho. Os agentes ambientais nocivos são múltiplos e suas especificidades, como concentração e frequência, determinam o nível de tolerância à exposição. Na escola, os riscos ambientais como ruído, poeira, temperatura e iluminação inadequadas, dentre outros, estão presentes, porém em grau leve. O tratamento acústico, de iluminação e de ventilação é indicado para controle desses riscos. Os documentos mostram situações de agravos à saúde dos trabalhadores em graus de risco muito maiores do que aqueles da docência. Não há explicitação de fatores inerentes à organização do trabalho e os cuidados com a voz limitam-se à profissão de teleoperador, o que pode servir de referência para o professor. Conclusão: A legislação trabalhista é ampla ao abarcar a diversidade de condições de trabalho e garantir a saúde dos trabalhadores. A docência apresenta riscos ocupacionais à saúde mais leves do que outras profissões; contudo, os fatores organizacionais do trabalho, assim como os distúrbios de voz, muito frequentes na docência, carecem de maior atenção da legislação no Brasil.
\end{abstract}

Descritores: Saúde do trabalhador; Fatores de risco; Voz; Docentes; Distúrbios da voz; Condições de trabalho; Legislação trabalhista

\section{INTRODUÇÃO}

A saúde do trabalhador integra a área da Saúde Pública e tem por objetivo o estudo e a intervenção nas relações entre o trabalho e a saúde, por meio da elaboração e aplicação de medidas articuladas que visem à promoção, proteção e recuperação da saúde do trabalhador, que são atribuições do Sistema Único de Saúde ${ }^{(1)}$.

A saúde no trabalho é condicionada por fatores sociais, econômicos, tecnológicos e organizacionais relacionados ao

Trabalho realizado na Faculdade de Fonoaudiologia, Centro de Ciências da Vida, da Pontifícia Universidade Católica de Campinas - PUC-Campinas Campinas (SP), Brasil, com bolsa de Iniciação Científica FAPIC/Reitoria concedida pela PUC-Campinas.

(1) Doutora, Professora da Faculdade de Fonoaudiologia da Pontifícia Universidade Católica de Campinas - PUC-Campinas - Campinas (SP), Brasil.

(2) Acadêmica da Faculdade de Fonoaudiologia da Pontifícia Universidade Católica de Campinas - PUC-Campinas - Campinas (SP), Brasil.

(3) Professora da Faculdade de Fonoaudiologia da Pontifícia Universidade Católica de Campinas - PUC-Campinas - Campinas (SP), Brasil.

Endereço para correspondência: Emilse Aparecida Merlin Servilha. Av. John Boyd Dunlop, $\mathrm{s} / \mathrm{n}^{\mathrm{o}}$, Jardim Ipaussurama, Campinas (SP), Brasil, CEP: 13060-904. E-mail: emilsemerlinservilha@puc-campinas.edu.br

Recebido em: 19/11/2009; Aceito em: 29/3/2010 perfil de produção e consumo, além de fatores de risco de natureza físicos, químicos, biológicos, mecânicos e ergonômicos presentes nos processos de trabalho particulares. Essa complexidade requereu a criação de uma Política Nacional de Segurança e Saúde do Trabalhador (PNSST), de caráter interministerial, para buscar a integralidade e articulação das ações desenvolvidas, assim como estabelecer diretrizes, responsabilidades institucionais, financiamento, gestão, acompanhamento e controle social nesse campo ${ }^{(2)}$.

Os fatores de risco à saúde devem ser analisados sob múltiplos aspectos: a intensidade, o tempo de exposição e a organização temporal da atividade, a duração do ciclo de trabalho, a distribuição das pausas ou a estrutura de horários ${ }^{(3)}$. As doenças relacionadas ao trabalho reconhecidas estão organizadas e relacionadas segundo sua taxonomia, nomenclatura e codificação na última revisão da Classificação Internacional de Doenças (CID-10), além de 198 entidades nosológicas para subsidiar o diagnóstico, tratamento, vigilância e o estabelecimento da relação da doença com o trabalho e outras providências decorrentes ${ }^{(4)}$.

Nesse contexto de políticas públicas que visam à saúde do trabalhador, o interesse do presente estudo recai sobre a relação entre docência e saúde, mais especificamente sobre 
os riscos ocupacionais nela presentes, pois ela é considerada, por muitos autores, como de risco para os distúrbios vocais ${ }^{(5,6)}$.

No que diz respeito aos distúrbios da voz relacionados ao trabalho, cabe considerar aspectos do ambiente como altos níveis de ruído, desconforto e choque térmico, ventilação inadequada, exposição a produtos químicos irritativos de vias aéreas superiores, como solventes e presença de poeira e/ou fumaça, entre outros ${ }^{(3,7-9)}$. Quanto aos aspectos organizacionais destacam-se a jornada prolongada, sobrecarga, acúmulo de atividades ou de funções, demanda vocal excessiva, ausência de pausas e de locais de descanso durante a jornada, falta de autonomia, ritmo estressante, trabalho sob forte pressão e insatisfação com o mesmo e/ou remuneração ${ }^{(10,11)}$.

As adversidades das mais diferentes ordens têm gerado alterações e de voz em professores como doenças da laringe e pregas vocais ${ }^{(12-14)}$, com consequentes queixas relacionadas à voz, como rouquidão, falhas e perda da voz, cansaço vocal, assim como sensações relacionadas à garganta como dor, secura e pigarro ${ }^{(15)}$.

O professor, como qualquer trabalhador, está exposto a uma série de fatores de risco que podem levá-lo ao adoecimento, absenteísmo e até afastamento definitivo do trabalho ${ }^{(11,16)}$. Quando esse agravo à saúde está sediado na laringe, leva à disfonia e incapacidade de utilizar a voz como instrumento de trabalho. Desta situação decorrem várias consequências negativas, pois o professor fica inapto a exercer a profissão para a qual se qualificou; a instituição escolar se obriga a substituir o docente, forma intermitente ou prolongada, até que o professor titular da classe retorne ao trabalho, ou seja, readaptado para nova função; há interferência no desempenho escolar do alunado, que estranha essa permuta, o que lhes requer grande capacidade de adaptação e, caso o professor insista em ministrar suas aulas mesmo disfonico, a audibilidade de sua voz não favorece sua compreensão pelos discentes ${ }^{(17)} \mathrm{e}$, finalmente, o Estado terá que arcar com os custos do tratamento do professor por meio do Sistema Único de Saúde (SUS) e de seus afastamentos do trabalho.

Apesar de a prevalência dos distúrbios da voz entre os professores ser um problema de saúde pública, a legislação trabalhista vigente não reconhece a relação da doença com a atividade docente e tampouco são explorados os condicionantes de gênero.

Nessa perspectiva, o objetivo desse estudo é analisar a legislação sobre riscos ocupacionais, com destaque para aqueles que possam comprometer a saúde e voz do professor.

\section{MÉTODOS}

Trata-se de pesquisa bibliográfica, de caráter qualitativo, que, inicialmente, buscou referência no site do Ministério do Trabalho e Emprego (MTE) ${ }^{(18)}$ para políticas públicas sobre saúde do trabalhador. Na literatura fonoaudiológica buscou-se artigos científicos para dispor dos resultados das investigações sobre a saúde e a voz do professor. Com isso, construiu-se um referencial teórico sobre os riscos ocupacionais mais presentes, condições do ambiente e organização do trabalho do professor e prevalência de distúrbios de voz nesse segmento profissional.

Em seguida, foram acessadas as Normas Reguladoras
(NR) sobre Saúde e Segurança no Trabalho, além de outros documentos de interesse. Procedeu-se à leitura detalhada de cada documento e os mesmos foram organizados em temas para melhor análise e destaque das informações pertinentes aos objetivos do estudo.

A análise destacou os riscos ocupacionais referidos, limites de tolerância, estratégias de controle, assim como aqueles específicos do ambiente escolar e repercussão sobre a saúde e voz do professor. Finalmente, detalharam-se os riscos ocupacionais e as normas de saúde e segurança do trabalho previstas na legislação para o profissional de telemarketing, por ser este o único trabalhador que, similarmente ao professor, usa a voz no desempenho profissional.

\section{RESULTADOS}

A legislação trabalhista conta com um detalhado conteúdo sobre a saúde e a segurança no trabalho, distribuído em Normas Regulamentadoras (NR), com temas e questões diversificadas, de modo a nortear as ações na área de saúde do trabalhador.

O Quadro 1 mostra os números e respectivos temas das $\mathrm{NR}$, relativos aos mais diversos tipos de agravos à saúde, assim como os serviços que devem ser constituídos, profissionais envolvidos e ações de promoção à saúde e prevenção às doenças requeridas para a área e protocolos de conduta que devem ser tomados diante das doenças ocupacionais.

As NR cujos conteúdos tangenciam as condições de trabalho do professor estão descritas no Quadro 2, assim como as queixas referidas por este segmento profissional quanto às condições de trabalho, presentes na literatura fonoaudiológica. Observa-se que, mesmo disponível em documentos oficiais, os requisitos básicos de conforto e segurança no trabalho nem sempre recebem a atenção devida para a execução do trabalho docente.

Limite de Tolerância refere-se à intensidade máxima ou mínima, considerando-se a natureza e o tempo de exposição ao fator de risco, que não causará dano à saúde do trabalhador, durante sua carreira.

A diversidade de agentes nocivos, assim como os diferentes tempos de exposição, de acordo com as especificidades do trabalho executado, requerem a determinação de níveis de tolerância distintos, e seu cálculo está padronizado em forma de tabelas na NR 15 e seus 14 anexos que envolvem, respectivamente: ruído contínuo e intermitente; ruído de impacto; exposição ao calor; radiações ionizantes; condições hiperbáricas; radiações não-ionizantes; vibrações; frio; umidade; agentes químicos cuja insalubridade é caracterizada por limite de tolerância e inspeção no local de trabalho; limites de tolerância para poeiras minerais; agentes químicos e agentes biológicos, que podem ser consultados a partir da detecção do fator de risco.

Segundo a mesma NR, as atividades laborais também são classificadas segundo seus gastos energéticos ou taxas de metabolismo, tais como: trabalho leve (125 a $150 \mathrm{kcal} / \mathrm{h})$ moderado (175 a $300 \mathrm{kcal} / \mathrm{h}$ ) e pesado (440 a $550 \mathrm{kcal} / \mathrm{h})$. O trabalho leve compreende manter-se sentado ou em pé com movimentos moderados de braços e/ou tronco e pernas; o trabalho moderado inclui movimentos vigorosos com braços e pernas 
Quadro 1. Número e tema das Normas Regulamentadoras Brasileiras (NR)

\begin{tabular}{|c|c|}
\hline NR & Tema da NR \\
\hline 1 & Disposições gerais \\
\hline 2 & Inspeção prévia \\
\hline 3 & Embargo ou interdição \\
\hline 4 & Serviços especializados em eng. de segurança e em medicina do trabalho \\
\hline 5 & Comissão interna de prevenção de acidentes \\
\hline 6 & Equipamentos de proteção individual - EPI \\
\hline 7 & Programas de controle médico de saúde ocupacional \\
\hline 8 & Edificações \\
\hline 9 & Programa de prevenção de riscos ambientais \\
\hline 10 & Segurança em instalações e serviços em eletricidade, transporte, movimentação, armazenagem e manuseio de materiais \\
\hline 11 & $\begin{array}{l}\text { Regulamento técnico de procedimentos para movimentação, armazenagem e manuseio de chapas de mármore, granito } \\
\text { e outras rochas }\end{array}$ \\
\hline 12 & Máquinas e equipamentos \\
\hline 13 & Caldeiras e vasos de pressão \\
\hline 14 & Fornos \\
\hline 15 & Atividades e operações insalubres \\
\hline 16 & Atividades e operações perigosas \\
\hline 17 & Ergonomia \\
\hline 17 Anexo I & Trabalho dos operadores de checkouts \\
\hline 17 Anexo II & Trabalho em teleatendimento/telemarketing \\
\hline 18 & Condições e meio ambiente de trabalho na indústria da construção \\
\hline 19 & Explosivos \\
\hline 19 Anexo I & Segurança e saúde na indústria de fogos de artificío e outros artefatos pirotécnicos \\
\hline 20 & Líquidos combustíveis e inflamáveis \\
\hline 21 & Trabalho a céu aberto \\
\hline 22 & Segurança e saúde ocupacional na mineração \\
\hline 23 & Proteção contra incêndios \\
\hline 24 & Condições sanitárias e de conforto nos locais de trabalho \\
\hline 25 & Resíduos industriais \\
\hline 26 & Sinalização de segurança \\
\hline 27 & Registro profissional do técnico de segurança do trabalho no MTB \\
\hline 28 & Fiscalização e penalidades \\
\hline 29 & Norma regulamentadora de segurança e saúde no trabalho portuário \\
\hline 30 & Norma regulamentadora de segurança e saúde no trabalho aquaviário \\
\hline 30 Anexo I & Pesca comercial e industrial \\
\hline 31 & Norma regulamentadora de segurança e saúde no trabalho na agricultura, pecuária, exploração florestal e aquicultura \\
\hline 32 & Segurança e saúde no trabalho em estabelecimento de saúde \\
\hline 33 & Segurança e saúde no trabalho em espaços confinados \\
\hline Rurais 1 & Disposições gerais \\
\hline 2 & Serviço especializado em prevenção de acidentes do trabalho rural - SEPATR \\
\hline 3 & Comissão interna de prevenção de acidentes do trabalho rural - CIPATR \\
\hline 4 & Equipamento individual - EPI \\
\hline 5 & Produtos químicos \\
\hline
\end{tabular}

na posição sentada ou em pé, trabalho leve ou moderado em máquina ou bancada, com alguma movimentação e ainda em movimento, trabalho moderado de levantar ou empurrar; e o trabalho pesado abarca ação intermitente de levantar, empurrar ou arrastar pesos e trabalho fatigante.

Diante da insalubridade, a saúde do trabalhador deve ser promovida e os riscos à sua saúde evitados, a partir da análise do ambiente e da organização da atividade laboral; determinação dos riscos e nível de exposição dos trabalhadores; antecipação dos riscos; definição de prioridades de avaliação; controle e avaliação de sua eficácia, além do registro, sistematização e divulgação dos resultados.
O controle dos riscos ocupacionais guarda relação direta com o tipo e concentração do agente, frequência de exposição, tipo de atividade e local de trabalho, dentre outras.

As estratégias de controle dos riscos ocupacionais nas atividades laborais em geral e na docência estão apresentadas no Quadro 3 e constata-se que muitas sugestões que podem favorecer os trabalhadores não cabem à situação de ensino, como, por exemplo, o uso de protetores auriculares na vigência de ruído. Contudo, outras, mesmo que em menor escala, podem ser adaptadas à escola, como o tratamento acústico dos locais de trabalho, o uso de ventiladores ou mesmo o resfriamento evaporativo por névoas para o conforto térmico, facilidades 
Quadro 2. Normas reguladoras que guardam relação com as condições de trabalho docente e queixas dos professores em relação ao ambiente de trabalho

\begin{tabular}{|c|c|c|}
\hline No/Tema & Síntese & Queixas dos professores \\
\hline $\begin{array}{l}\text { NR } 8 \\
\text { Edificações }\end{array}$ & $\begin{array}{l}8.2 \text { Os locais de trabalho devem ter a altura do piso ao teto, pé direito, de acordo } \\
\text { com as posturas municipais, atendidas as condições de conforto, segurança e } \\
\text { salubridade, estabelecidas na Portaria } 3.214 / 78\end{array}$ & $\begin{array}{l}\text { Teto muito baixo, adaptação de residên- } \\
\text { cias, galpões e até contêineres para } \\
\text { instalação de salas de aula }\end{array}$ \\
\hline \multirow[t]{5}{*}{$\begin{array}{l}\text { NR } 9 \\
\text { Programa de } \\
\text { Prevenção de } \\
\text { riscos ambi- } \\
\text { entais }\end{array}$} & $\begin{array}{l}\text { 9.1.1 Obrigatoriedade da elaboração e implementação, por parte do empregador, } \\
\text { do Programa de Prevenção de Riscos Ambientais - PPRA, visando à preservação } \\
\text { da saúde e da integridade dos trabalhadores, através da antecipação, reconhe- } \\
\text { cimento, avaliação e consequente controle da ocorrência de riscos ambientais } \\
\text { existentes ou que venham a existir no ambiente de trabalho [...] }\end{array}$ & $\begin{array}{l}\text { Não há uma preocupação formal nesse } \\
\text { sentido }\end{array}$ \\
\hline & $\begin{array}{l}\text { 9.1.5 Consideram-se riscos ambientais os agentes físicos, químicos e biológicos } \\
\text { existentes nos ambientes de trabalho que, em função de sua natureza, concen- } \\
\text { tração ou intensidade e tempo de exposição, são capazes de causar danos à } \\
\text { saúde do trabalhador }\end{array}$ & Presença de riscos ambientais variados \\
\hline & $\begin{array}{l}\text { 9.1.5.1 Consideram-se agentes físicos as diversas formas de energia a que possam } \\
\text { estar expostos os trabalhadores, tais como: ruído, vibrações, pressões anormais, } \\
\text { temperaturas extremas, radiações ionizantes, radiações não ionizantes, bem como } \\
\text { o infra-som e o ultra-som. }\end{array}$ & $\begin{array}{l}\text { Altos níveis de ruído e desconforto } \\
\text { térmico, com salas de aula muito frias } \\
\text { no inverno e muito quentes no verão. }\end{array}$ \\
\hline & $\begin{array}{l}\text { 9.1.5.2 Consideram-se agentes químicos as substâncias, compostos ou produtos } \\
\text { que possam penetrar no organismo pela via respiratória, nas formas de poeiras, } \\
\text { fumos, névoas, neblinas, gases ou vapores, ou que, pela natureza da atividade } \\
\text { de exposição, possam ter contato ou ser absorvidos pelo organismo através da } \\
\text { pele ou por ingestão (asbesto ou amianto) }\end{array}$ & $\begin{array}{l}\text { Pó de giz, poeira, terra, areia, pó acu- } \\
\text { mulado nos livros, móveis, etc. }\end{array}$ \\
\hline & $\begin{array}{l}\text { 9.1.5.3 Consideram-se agentes biológicos as bactérias, fungos, bacilos, parasitas, } \\
\text { protozoários, vírus, entre outros. }\end{array}$ & $\begin{array}{l}\text { Infecções de vias aéreas superiores } \\
\text { frequentes no inverno favorecidas pelo } \\
\text { ambiente fechado e excesso de alunos }\end{array}$ \\
\hline \multirow[t]{4}{*}{$\begin{array}{l}\text { NR } 17 \\
\text { Ergonomia }\end{array}$} & $\begin{array}{l}\text { 17.1.2 Para avaliar a adaptação das condições de trabalho às características psico- } \\
\text { fisiológicas dos trabalhadores, cabe ao empregador realizar a análise ergonômica } \\
\text { do trabalho, devendo a mesma abordar, no mínimo, as condições de trabalho, } \\
\text { conforme estabelecido nesta Norma Regulamentadora. }\end{array}$ & $\begin{array}{l}\text { A altura das lousas, cadeiras e mesas } \\
\text { nem sempre estão adequados às carac- } \\
\text { terísticas físicas dos professores }\end{array}$ \\
\hline & $\begin{array}{l}\text { 17.5.2 Nos locais de trabalho onde são executadas atividades que exijam solicitação } \\
\text { intelectual e atenção constantes [...] são recomendadas as seguintes condições de } \\
\text { conforto: a) níveis de ruído de acordo com o estabelecido na NBR } 10152, \text { norma } \\
\text { brasileira registrada no INMETRO;b) índice de temperatura efetiva entre } 20^{\circ} \mathrm{C} \\
\text { (vinte) e } 23^{\circ} \mathrm{C} \text { (vinte e três graus centígrados); c) velocidade do ar não superior a } \\
0,75 \mathrm{~m} / \mathrm{s} \text {; d) umidade relativa do ar não inferior a } 40 \text { (quarenta) por cento }\end{array}$ & $\begin{array}{l}\text { Níveis de ruído excessivos, falta de } \\
\text { desconforto térmico, pouca ventila- } \\
\text { ção, presença de umidade e higiene } \\
\text { deficitária }\end{array}$ \\
\hline & $\begin{array}{l}\text { 17.5.3 Em todos os locais de trabalho deve haver iluminação adequada, natural } \\
\text { ou artificial, geral ou suplementar, apropriada à natureza da atividade. }\end{array}$ & Iluminação insuficiente \\
\hline & $\begin{array}{l}\text { 17.6.2 A organização do trabalho, para efeito desta NR, deve levar em considera- } \\
\text { ção, no mínimo: a) as normas de produção; b) o modo operatório; c) a exigência } \\
\text { de tempo; d) a determinação do conteúdo de tempo; e) o ritmo de trabalho; f) o } \\
\text { conteúdo das tarefas. }\end{array}$ & $\begin{array}{l}\text { Na organização do trabalho há queixa } \\
\text { de fiscalização constante, ritmo de } \\
\text { trabalho estressante, excesso de ativi- } \\
\text { dades e necessidade de levar trabalho } \\
\text { para casa }\end{array}$ \\
\hline $\begin{array}{l}\text { NR } 21 \\
\text { Trabalhos a } \\
\text { céu aberto }\end{array}$ & $\begin{array}{l}21.2 \text { Exige-se proteção aos trabalhadores contra a insolação excessiva, o calor, } \\
\text { o frio, a umidade e os ventos inconvenientes. }\end{array}$ & $\begin{array}{l}\text { Ventos e frio que agridem a saúde e a } \\
\text { voz do professor }\end{array}$ \\
\hline \multirow{3}{*}{$\begin{array}{l}\text { NR } 24 \\
\text { Condições de } \\
\text { controle e de } \\
\text { Conforto nos } \\
\text { locais de tra- } \\
\text { balho }\end{array}$} & $\begin{array}{l}\text { 24.1.3 Os locais onde se encontrarem instalações sanitárias deverão ser submeti- } \\
\text { dos a processo permanente de higienização, de sorte que sejam mantidos limpos } \\
\text { e desprovidos de quaisquer odores, durante toda a jornada de trabalho. }\end{array}$ & $\begin{array}{l}\text { Falta de higiene nos banheiros e uso de } \\
\text { produtos químicos irritantes na limpeza }\end{array}$ \\
\hline & $\begin{array}{l}\text { 24.3.15 Nos estabelecimentos em que trabalhem mais de } 30 \text { (trinta) até } 300 \\
\text { (trezentos) empregados [...] deverão ser asseguradas aos trabalhadores condições } \\
\text { suficientes de conforto para as refeições. }\end{array}$ & $\begin{array}{l}\text { Não há local próprio para a refeição ou } \\
\text { lanche do docente. }\end{array}$ \\
\hline & $\begin{array}{l}\text { 24.3.15.1 As condições de conforto [...] deverão preencher os seguintes requisitos } \\
\text { mínimos: a) local adequado, fora da área de trabalho; b) piso lavável; c) limpeza, } \\
\text { arejamento e boa iluminação; d) mesas e assentos em número correspondente ao } \\
\text { de usuários; e) lavatórios e pias instalados nas proximidades ou no próprio local; } \\
\text { f) fornecimento de água potável aos empregados. }\end{array}$ & Local de conforto inadequado \\
\hline
\end{tabular}


Quadro 3. Estratégias de controle dos riscos ocupacionais nas atividades em geral e na docência

\begin{tabular}{|c|c|c|}
\hline \multirow{2}{*}{ Risco à saúde } & \multicolumn{2}{|l|}{ Estratégias de controle } \\
\hline & Geral & Escola \\
\hline Ruídos & $\begin{array}{l}\text { Enclausuramento da fonte do ruído, uso de Equipamento } \\
\text { de Proteção Individual (EPI), tratamento acústico dos } \\
\text { locais de trabalho. }\end{array}$ & $\begin{array}{l}\text { Tratamento acústico das salas de aula, de modo especial, } \\
\text { no planejamento de sua construção. Para escolas } \\
\text { em funcionamento, reorganização dos espaços de } \\
\text { atividades ruidosas e não ruidosas, como o recreio das } \\
\text { crianças, aulas de educação física, música, dentre outras. } \\
\text { Colocação de material poroso nas paredes, cortinas } \\
\text { grossas e plantas. }\end{array}$ \\
\hline Temperatura & $\begin{array}{l}\text { Sistema Ventiladores e Exaustores - os ventiladores fazem } \\
\text { a circulação do ar ambiente, melhorando a sensação } \\
\text { térmica. Para que a ventilação seja eficiente o sistema } \\
\text { deve ser projetado para realizar, no mínimo, } 20 \text { trocas } \\
\text { de ar por hora. } \\
\text { Sistemas de Insuflamento que captam o ar fresco e limpo } \\
\text { e o insuflam através de sistemas motorizados com dutos } \\
\text { e difusores de ar. } \\
\text { Revestimento de Teto como cerâmica, resina e aplicação } \\
\text { de polipropileno, para evitar o aquecimento do ar interno } \\
\text { resultante da ação dos raios solares sobre o telhado e o } \\
\text { que o mesmo transfira o calor para dentro do ambiente. } \\
\text { Resfriamento Evaporativo por Névoas que controla a } \\
\text { temperatura e umidade do ar por meio da evaporação da } \\
\text { água. Produzem névoa de rápida evaporação, que não } \\
\text { precipita e não molha, promovendo a troca de calor entre } \\
\text { o ar e a água, abaixando a temperatura ambiente. }\end{array}$ & $\begin{array}{l}\text { Revestimento de Teto como cerâmica, resina e aplicação } \\
\text { de polipropileno, para evitar o aquecimento do ar interno } \\
\text { resultante da ação dos raios solares sobre o telhado e o } \\
\text { que o mesmo transfira o calor para dentro do ambiente. } \\
\text { Planejamento do piso e paredes que tragam conforto } \\
\text { térmico e incidência de sol matutino. }\end{array}$ \\
\hline Poeira & $\begin{array}{l}\text { Substituição de tecnologias de produção por outras menos } \\
\text { arriscadas para a saúde; medidas rigorosas de higiene } \\
\text { e segurança do trabalho, como adoção de sistemas de } \\
\text { ventilação local exaustora e geral adequados e eficientes; } \\
\text { diminuição do tempo de exposição e do número de } \\
\text { trabalhadores expostos. }\end{array}$ & $\begin{array}{l}\text { Limpeza satisfatória da lousa, salas de aula e pátios, } \\
\text { preferencialmente com uso de água e substâncias não } \\
\text { irritativas às vias aéreas dos professores e alunos. }\end{array}$ \\
\hline $\begin{array}{l}\text { Bactérias, fungos, } \\
\text { bacilos, parasitas, } \\
\text { protozoários, vírus, } \\
\text { entre outros }\end{array}$ & $\begin{array}{l}\text { Medidas de limpeza geral dos ambientes de trabalho e } \\
\text { facilidades para higiene pessoal, recursos para banhos, } \\
\text { lavagem das mãos, braços, rosto e troca de vestuário. } \\
\text { Re-estruturação na organização do trabalho que resultem } \\
\text { na minimização do número de trabalhadores expostos, } \\
\text { do tempo de exposição e a redução de fatores geradores } \\
\text { de estresse. } \\
\text { Monitoramento sistemático das concentrações de fumos, } \\
\text { névoas e poeiras no ar ambiente. }\end{array}$ & $\begin{array}{l}\text { Medidas de limpeza geral dos ambientes de trabalho e } \\
\text { facilidades para lavagem das mãos. Ambiente arejado e } \\
\text { espaçoso. }\end{array}$ \\
\hline
\end{tabular}

para lavagem das mãos, entre outras.

Considerando que a NR 17 - Trabalho em Atendimento/ Telemarketing (Anexo II) é a única que faz referência ao uso profissional da voz, optou-se por detalhar seu conteúdo no Quadro 4 para compará-lo com a situação do professor. Nela podem ser vistas as normas específicas para se propiciar ao trabalhador um ambiente saudável, proteção do mesmo em situações de dificuldade como episódios de violência e ainda ações de vigilância em saúde, inclusive qualificação em relação à saúde e à voz.

\section{DISCUSSÃO}

A análise dos documentos oficiais sobre saúde e segurança no trabalho evidencia que eles foram elaborados, de modo geral, tendo como parâmetro os riscos ocupacionais que podem trazer prejuízos à saúde do trabalhador (Quadro 1). Especificidades ocorrem nas NR 17 - Anexo I e II (Operadores de Checkouts e Trabalho em Teleatendimento), 29 (Trabalho Portuário), 30 (Trabalho Aquaviário), 31 (Trabalho na Agricultura, Pecuária, Exploração Florestal e Aquicultura) e 32 (Trabalho em Estabelecimento de Saúde), que focalizam profissões específicas, possivelmente para detalhar questões inerentes às mesmas e que não estavam previstas em documentos anteriores. Cabe destaque à profissão de teleoperador, ainda recente, e que traz como inovação a referência ao uso da voz.

A comparação entre as NRs que indicam as condições de trabalho em qualquer função e as queixas dos professores (Quadro 2) permite mostrar que na legislação estão especificadas normas para as instalações físicas, prevenção de riscos 
Quadro 4. Condições de trabalho e voz em teleoperadores

\begin{tabular}{|c|c|c|}
\hline Categorias & Fatores de risco & Providências \\
\hline \multirow{4}{*}{ Ambiente de trabalho } & Ruído & Isolamento acústico do ruído externo e níveis de ruído de até $65 \mathrm{~dB}(\mathrm{~A})$ \\
\hline & Temperatura & $20^{\circ}$ a $23^{\circ} \mathrm{C}$ \\
\hline & Ventilação & Velocidade do ar não superior a $0,75 \mathrm{~m} / \mathrm{s}$ \\
\hline & Umidade & Umidade relativa do ar não inferior a $40 \%$ \\
\hline \multirow{5}{*}{$\begin{array}{l}\text { Organização do } \\
\text { trabalho }\end{array}$} & Jornada de trabalho & Seis horas diárias, incluídas as pausas com escalas laborais flexíveis \\
\hline & $\begin{array}{l}\text { Relação entre trabalhador } \\
\text { e demanda de produção }\end{array}$ & $\begin{array}{l}\text { Evitar sobrecarga habitual ao trabalhador e garantir pausas e intervalos para prevenir } \\
\text { sobrecarga psíquica e física. }\end{array}$ \\
\hline & Local para descanso & $\begin{array}{l}\text { Ambientes confortáveis para descanso e recuperação durante as pausas, fora dos } \\
\text { ambientes de trabalho [...] onde estejam disponíveis assentos, facilidades de água } \\
\text { potável, instalações sanitárias e lixeiras com tampa. }\end{array}$ \\
\hline & Violência & $\begin{array}{l}\text { Pausas no trabalho imediatamente após operação, onde haja ocorrido ameaças, abuso } \\
\text { verbal, agressões ou que tenha sido especialmente desgastante, que permitam ao } \\
\text { operador recuperar-se e socializar conflitos e dificuldades com colegas, supervisores } \\
\text { ou profissionais de saúde ocupacional capacitados especialmente para tal acolhimento. }\end{array}$ \\
\hline & Autonomia no trabalho & $\begin{array}{l}\text { Com a finalidade de reduzir o estresse dos operadores, devem ser minimizados os } \\
\text { conflitos e ambiguidades de papéis nas tarefas a executar, estabelecendo-se claramente } \\
\text { as diretrizes quanto a ordens e instruções de diversos níveis hierárquicos, autonomia } \\
\text { para resolução de problemas, autorização para transferência de chamadas e consultas } \\
\text { necessárias a colegas e supervisores. }\end{array}$ \\
\hline \multirow{4}{*}{ Saúde e voz } & Capacitação & $\begin{array}{l}\text { Conhecer as formas de adoecimento relacionadas à sua atividade, suas causas, efeitos } \\
\text { sobre a saúde e medidas de prevenção e deve incluir noções sobre os fatores de risco } \\
\text { para a saúde em teleatendimento/telemarketing. } \\
\text { Medidas de prevenção indicadas para a redução dos riscos relacionados ao trabalho; } \\
\text { informações sobre os sintomas de adoecimento que possam estar relacionados a } \\
\text { atividade de teleatendimento/telemarketing, principalmente os que envolvem o sistema } \\
\text { osteomuscular, a saúde mental, as funções vocais, auditivas e acuidade visual dos } \\
\text { trabalhadores; duração de } 04 \text { (quatro) horas na admissão e reciclagem a cada } 06 \text { (seis) } \\
\text { meses, independentemente de campanhas educativas que sejam promovidas pelos } \\
\text { empregadores; distribuição obrigatória de material didático impresso com o conteúdo } \\
\text { apresentado; realização durante a jornada de trabalho. }\end{array}$ \\
\hline & Hidratação & Disponibilidade irrestrita e próxima de água potável (NR 24). \\
\hline & Saúde vocal & $\begin{array}{l}\text { Implementar, entre outras medidas: modelos de diálogos que favoreçam micropausas } \\
\text { e evitem carga vocal intensiva do operador; redução do ruído de fundo e estímulo à } \\
\text { ingestão frequente de água potável fornecida gratuitamente aos operadores. }\end{array}$ \\
\hline & Vigilância à saúde & $\begin{array}{l}\text { Implementar um programa de vigilância epidemiológica para deteç̧ão precoce de casos } \\
\text { de doenças relacionadas ao trabalho comprovadas ou objeto de suspeita, que inclua } \\
\text { procedimentos de vigilância passiva [...] e vigilância ativa, por intermédio de exames } \\
\text { médicos dirigidos que incluam, além dos exames obrigatórios por norma, coleta de } \\
\text { dados sobre sintomas referentes aos aparelhos psíquico, osteomuscular, vocal, visual } \\
\text { e auditivo, analisados e apresentados com a utilização de ferramentas estatísticas e } \\
\text { epidemiológicas. }\end{array}$ \\
\hline
\end{tabular}

ambientais, trabalho a céu aberto e, de modo especial, a ergonomia e as condições de controle e de conforto nos locais de trabalho. A busca na literatura sobre os riscos ocupacionais relacionados ao professor mostra que, de modo geral, em relação a edificações há queixas em relação à altura do teto e à adaptação de prédios construídos para outra finalidade para abrigar salas de aulas. Por outro lado, um Programa de Prevenção de Riscos Ocupacionais parece não fazer parte da agenda na escola, como ocorre de forma sistemática nas empresas. Essa despreocupação talvez decorra da compreensão de que a escola está alijada dessas questões, uma vez que lida com o conhecimento, embora, lá, os professores sejam trabalhadores. Apesar disso, os altos e frequentes ruídos prejudicam a saúde geral, auditiva e vocal dos professores e interferem na qualidade do ensino ${ }^{(19-21)}$. Isto ocorre, possivelmente, porque no momento da construção da escola não há preocupação com o conforto acústico e nem ações efetivas para contornar esse problema quando ele é detectado. Outra questão relevante é a ergonomia abordada no ambiente de trabalho como de relevância para o bom desempenho do trabalhador. São notórias as queixas dos docentes em relação aos móveis, dores nos braços pelo uso constante da lousa e dores nas pernas e problemas de coluna por manterem-se em pé por longos períodos ${ }^{(22)}$, indicando que a forma como trabalham muitas vezes carece da ergonomia necessária. Finalmente, as condições de controle e de conforto nos locais de trabalho também não são adequadas, uma vez que, de modo geral, há referências dos docentes em relação ao pouco espaço para sua movimentação em sala de 
aula devido ao número excessivo de alunos por turma ${ }^{(12,14)}$. O trabalho a céu aberto de que fala a NR 21 se refere a situações bastante adversas aos trabalhadores como aqueles da construção civil, dentre outras, muito diferentes daqueles docentes que ministram suas aulas em quadras, por exemplo. Nesses casos, o vento, a chuva, o sol e o frio trazem desconforto ao professor, porém não na frequência e intensidade de outros trabalhadores. Contudo os docentes utilizam a voz como instrumento de trabalho e por isso teriam um agravante em relação à sua saúde e voz. Finalmente, em relação às condições de controle e de conforto nos locais de trabalho (mencionadas na NR 24), os professores referem a má higienização dos banheiros ${ }^{(6)} \mathrm{e}$ local e tempo inadequados para descanso e lanche ${ }^{(11)}$.

Em relação aos tipos de riscos ambientais presentes na atividade laboral do professor e respectivos níveis de tolerância, o ruído, na categoria de riscos físicos, pode gerar agravos à saúde na área auditiva e vocal, além de perda da concentração e reflexos, irritação permanente, dores de cabeça, estresse, distúrbios cardiovasculares, fadiga, distúrbios hormonais, gastrite, disfunção digestiva, aumento da frequência cardíaca, alergias, contração dos vasos sanguíneos e distúrbios do sono, entre outros ${ }^{(23)}$. Embora na escola seu limite de tolerância seja de $50 \mathrm{~dB}^{(24)}$ o que se observa é que maior parte do tempo esse limite é ultrapassado pela convergência de sons oriundos do ambiente externo, como tráfego e construções, e interno, como o pátio, as aulas de Educação Física, recreio e professores ministrando suas aulas. Somado a tudo isso, os próprios sons gerados dentro da sala de aula, como arrastar de pés e carteiras, ruído de ventilador e vozes dos professores e alunos criam um ambiente de sons intensos e ininterruptos, impróprios para o ensino-aprendizagem, pois, ao longo do tempo, ocorre estafa de professores e alunos, que prejudica a concentração dos alunos e deteriora a qualidade da voz dos docentes. Estas consequências têm sido reportadas nas pesquisas fonoaudiológicas internacionais e nacionais ${ }^{(17,20)}$. Quanto aos riscos químicos, a poeira é o agente mais frequente na escola, contudo ela não se refere aquela advinda de asbesto, manganês, sílica ou amianto de que fala a NR 15, cujos malefícios para a saúde são notórios. Trata-se do pó de giz, terra e pó caseiro, muito menos nocivos e com menor concentração e frequência de exposição do que os citados anteriormente, porém agressivos ao sistema respiratório, em especial para aqueles professores com tendência a alergias, com repercussões negativas sobre a voz ${ }^{(25)}$. Finalmente, como agentes biológicos, têm-se as bactérias, fungos, bacilos, parasitas, protozoários, vírus, entre outros, presentes na escola, em especial no período de frio, que favorece a aglomeração em ambientes fechados. Com isso, o professor fica mais exposto a gripes, resfriados e infecções respiratórias ${ }^{(26)}$, dificultando o uso profissional da voz.

Considerando-se o gasto energético, segundo a NR 15, o trabalho docente realizado em posição sentada ou em pé com movimentos moderados com braços e pernas gastaria cerca de $150 \mathrm{kcal} / \mathrm{hora}$, sendo, portanto, considerado do tipo leve. Contudo, apesar do baixo dispêndio de energia física, não se pode negligenciar que o professor, para conduzir a classe e desempenhar sua função de mediador entre o aluno e o conhecimento, precisa empregar habilidades físicas, cognitivas e afetivas de forma sinérgica, com consequente sobrecarga das funções psicofisiológicas, e ocorrência de doenças e afastamento do trabalho devido a distúrbios mentais ${ }^{(27)}$. Nessa perspectiva, na docência, o pouco esforço físico é substituído pelas demandas cognitivas e psíquicas.

As NRs apresentam os múltiplos riscos ocupacionais presentes no local de trabalho de qualquer trabalhador e também do professor, e os níveis de tolerância encontram-se padronizados a partir da periculosidade do agente, frequencia e tempo de exposição. Daqueles riscos apresentados na NR 15 e seus anexos, o ruído, calor, frio, umidade, poeiras minerais, agentes químicos e biológicos, também podem ser analisados no ambiente escolar, porém sua intensidade é evidentemente mais tênue do que para outras categorias profissionais, contudo o adoecimento do professor continua a ocorrer. Diante disso, faz-se necessário definir os agentes e níveis de tolerância que compõem o contexto específico da escola, local em que um trabalhador singular desenvolve seu trabalho, essencialmente cognitivo, dialógico e interativo. Podem ser tomadas como base outras características do trabalho, por exemplo, aquelas decorrentes da organização do trabalho, que, juntas, criam um conjunto de adversidades que resultam em prejuízo à saúde e à voz do docente.A implementação de estratégias para minimização ou eliminação de riscos ocupacionais é vital para garantir um local de trabalho salubre e satisfatório. Assim, a comparação das providências para controle do excesso de ruído, temperatura muito elevada ou muito baixa, poeira e bactérias, vírus, entre outros (Quadro 3) nos locais de trabalho mostra que, dentre aquelas indicadas nos documentos oficiais, nem sempre há possibilidade de aplicação na escola. Em relação ao ruído de uma máquina, ela pode ser enclausurada, mas na escola, usualmente, são as próprias pessoas que lá vivem, professores e alunos, os responsáveis pelo ruído. Desta forma, a medida não se aplica. Contudo, merecem atenção os ruídos advindos da rua ou de outras atividades desenvolvidas na escola, os quais podem ser atenuados pelo revestimento das paredes e pisos da sala de aula, alternativas viáveis e econômicas. Quanto à poeira, temperatura e microorganismos, a limpeza eficiente e a ventilação também podem ser ajustadas, sem muito custo e com repercussões valiosas sobre a saúde da comunidade escolar.

Finalmente, cabe destaque às condições de trabalho em teleoperadores estabelecido pela NR 17, Anexo II, tomado nesse trabalho como referência para análise da docência (Quadro 4). A profissão de teleoperador é bem mais recente do que a docência e conta com um contingente muito menor de profissionais no Brasil, contudo, desde 02/04/2007, com a publicação da NR 17 no Diário Oficial da União, muito de seus direitos trabalhistas estão garantidos. $\mathrm{O}$ documento explicita normas a serem cumpridas sobre o ambiente de trabalho (ruído, temperatura, ventilação e umidade) e sua organização (jornada de trabalho, relação trabalhador e demanda de produção, local para descanso, violência, autonomia no trabalho) e adiciona aspectos sobre saúde e voz incluindo capacitação, hidratação, saúde vocal e vigilância à saúde. Pela primeira vez, o uso da voz de forma profissional recebe atenção e cobertura legal em relação à capacitação, inclusive com qualificação semestral, regras de uso, tempo de uso, disponibilidade de água e vigilância, com exames obrigatórios de voz e audição. Toda essa 
atenção em relação à voz e à audição mostra-se extremamente pertinente e seria necessária e prudente também em relação à saúde dos professores. No entanto, apesar do grande número de profissionais no país e dos afastamentos e licenças médicas, os professores não recebem a mesma atenção que os teleoperadores. A justificativa para isso pode estar no fato de os teleoperadores estarem ligados ao setor econômico sob responsabilidade de grandes empresas, enquanto os docentes pertencem à área da educação e, quando se considera as escolas de educação infantil e ensino fundamental, são, em sua maioria, funcionários de órgãos públicos municipais e estaduais. Implantar ações de saúde, inclusive aquelas pertinentes à área vocal e auditiva requer recursos, os quais nem sempre estão disponíveis quando se trata da esfera pública. Exemplo disso são as iniciativas de Leis de Saúde Vocal criadas em nível municipal e estadual, em todo o Brasil, que prescrevem um curso anual para qualificação de professores em serviço e antes do ingresso, que não são executados com a justificativa de falta de verbas ${ }^{(28)}$.

A avaliação dos documentos oficiais que legislam sobre normas de saúde e segurança no trabalho ressalta que, exceto pela NR 17 Anexo II anteriormente destacada, não há explicitação dos fatores de risco presentes na organização do trabalho como fiscalização permanente, excesso de trabalho, pouca autonomia, violência, falta de reconhecimento social, dentre outros, presentes na atividade docente. O professor é um trabalhador que lida com o conhecimento, está diariamente em contato com os alunos, aqueles que recebem seu trabalho, e por isso está sujeito a frustrações, estresse, ansiedade e depressão compatíveis com a chamada Síndrome de Burnout. Esta síndrome está relacionada como doença do trabalho ${ }^{(1)}$ e trata-se de um tipo de estresse ligado a atividade laboral presente em profissionais envolvidos na atividade do cuidado, de forma direta, contínua e altamente emocional, o que acarreta exaustão emocional, isto é, falta ou carência de energia, entusiasmo e sentimento de esgotamento de recursos; despersonalização, pois passa a tratar como objetos aqueles relacionados com o trabalho, e restrição da realização pessoal no trabalho acompanhada de autoavaliação negativa ${ }^{(29)}$. Por outro lado, a lista de Doenças Relacionadas ao Trabalho ${ }^{(4)}$ inclui a disfonia como um sintoma da laringotraqueíte, grupo X da CID-10, capítulo 15, mas não menciona o uso excessivo da voz no trabalho como fator de risco.

Tudo isso mostra que há ainda muito que ser alcançado no que diz respeito aos direitos do professor, assim como de outros usuários profissionais da voz.

\section{CONCLUSÃO}

A legislação trabalhista é ampla ao abarcar a diversidade de condições de trabalho e garantir a saúde dos trabalhadores. A docência apresenta riscos ocupacionais à saúde mais leves do que outras profissões, contudo, os fatores organizacionais do trabalho, assim como os distúrbios de voz, muito frequentes na docência, carecem de maior atenção da legislação no Brasil.

A NR 17, sobre o trabalho em telemarketing, traz avanços na legislação nesses aspectos e pode se tornar referência para a ampliação desses mesmos direitos aos outros profissionais da voz, dentre eles o professor.

\begin{abstract}
Purpose: To analyze the legislation regarding occupational risks, highlighting those related to teacher's health and voice. Methods: A bibliographic search of qualitative nature regarding the public policies about Health and Security at Work was carried out. The Regulatory Standards were read and their contents analyzed and organized into categories, detaching those from the scholar environment. Results: The 33 regulatory standards focus the risk factors, tolerance levels, and control for health and security at work. The harmful environmental agents are multiple and their specificities, such as concentration and frequency, determine the level of tolerance to exposition. At school, the environmental risks like noise, dust, temperature and inadequate lighting, among others, are present, however in a mild degree. The acoustic, lighting and exhaust ventilation treatments are indicated for the control of such risks. The documents show situations of worsening of the workers' health in much higher degrees of risk than those from teaching activities. There is no explicitation of factors inherent to the work organization, and the care with the voice is limited to the profession of telesales workers, which can serve as a reference to the teacher's work. Conclusion: Labor legislation is ample to cover the diversity of work conditions and to ensure the workers' health. Teaching presents milder occupational risks to health than other professions; nevertheless, the organizational factors of work, as well as voice disorders, very frequent in this activity, demand greater attention from Brazilian legislation.
\end{abstract}

Keywords: Occupational health; Risk factors; Voice; Faculty; Voice disorders; Working conditions; Legislation, labor

\title{
REFERÊNCIAS
}

1. Brasil. Ministério da Saúde. Organização Pan-Americana da Saúde/ Brasil. Doenças relacionadas ao trabalho: manual de procedimentos para os serviços de saúde [Internet]. Brasília: Ministério da Saúde;
2001. Série A. Normas e Manuais Técnicos; n. 114. [citado 2008 Ago 12]. Disponível em http://www.opas.org.br/sistema/arquivos/ Saudedotrabalhador.pdf. 
2. Brasil. Política Nacional de Segurança e Saúde do Trabalhador. Ministério da Saúde. Brasília, Novembro de 2004 [Internet]. [citado 2008 Ago 12]. Disponível em http://www.previdenciasocial.gov.br/ arquivos/office/3_081014-105206-701.pdf.

3. Secretaria de Estado da Saude. Centro de Referência em Saúde do Trabalhador. Coordenadoria de Controle de Doenças. Distúrbios de voz relacionados ao trabalho. Bol Epidemiol Paul. 2006;3(26):16-22.

4. Brasil. Ministério da Saúde. Portaria No 1339/GM, de 18 de novembro de 1999. Institui a Lista de Doenças relacionadas ao Trabalho, a ser adotada como referência dos agravos originados no processo de trabalho no Sistema Único de Saúde, para uso clínico e epidemiológico [Internet]. [citado 2008 Out 4]. Disponível em: http://portal.saude.gov. br/portal/arquivos/pdf/lista_doencas_relacionadas_trabalho.pdf.

5. Roy N, Merrill RM, Thibeault S, Parsa RA, Gray SD, Smith EM. Prevalence of voice disorders in teachers and the general population. J Speech Lang Hear Res. 2004;47(2):281-93.

6. Ferreira LP, Giannini SPP, Figueira S, Silva EE, Karmann DF, Souza TMT. Condições de produção vocal de professores da Prefeitura do Município de São Paulo. Distúrb Comun. 2003;14(2):275-307.

7. Veodato TG, Monteiro MI. Perfil sociodemográfico e condições de saúde e trabalho dos professores de nove escolas estaduais paulistas. Rev Esc Enferm USP. 2008;42(2):291-7.

8. Medeiros AM. Disfonia e condições de trabalho das professoras da rede municipal de ensino de Belo Horizonte [dissertação]. Belo Horizonte: Faculdade de Medicina da Universidade Federal de Minas Gerais; 2006.

9. Lemos S, Rumel D. Ocorrência de disfonia em professores de escolas públicas da rede municipal de ensino de Criciúma-SC. Rev Bras Saúde Ocup. 2005;30(112):7-13.

10. Delcor NS, Araújo TM, Reis EJFB, Porto LA, Carvalho FM, Silva MO, et al. Condições de trabalho e saúde dos professores da rede particular de ensino de Vitória da Conquista, Bahia, Brasil. Cad Saúde Pública = Rep Public Health. 2004;20(1):187-96.

11. Marchiori F, Barros MEB, Oliveira SP. Atividades de trabalho e saúde dos professores: o programa de formação como estratégia de intervenção nas escolas. Trab Educ Saúde. 2005;3(1):143-70.

12. Porto LA, Reis IC, Andrade JM, Nascimento CR, Carvalho FM. Doenças ocupacionais em professores atendidos pelo Centro de Estudos da Saúde do Trabalhor (CESAT). Rev Baiana Saúde Pública. 2004;28(1):33-49.

13. Palheta Neto FX, Rebelo Neto OB, Ferreira Filho JSS, Palheta ACT, Rodrigues LG, Silva FA. Relação entre as condições de trabalho e a autoavaliação em professores do ensino fundamental. Arq Int Otorrinolaringol. 2008;12(2):230-8.

14. Araújo TM, Reis EJFB, Carvalho FM, Porto LA, Reis IC, Andrade JM. Fatores associados a alterações vocais em professoras. Cad Saúde Pública = Rep Public Health. 2008;24(6):1229-38.
15. Silvério KCA, Gonçalves CGO, Penteado RZ, Vieira TPG, Libardi A, Rossi D. Ações em saúde vocal: proposta de melhoria do perfil vocal de professores. Pró-Fono. 2008;20(3):177-82.

16. Jardim R, Barreto SM, Assunção AA. Condições de trabalho, qualidade de vida e disfonia entre docentes. Cad Saúde Pública $=$ Rep Public Health. 2007;23(10):2439-61.

17. Rogerson J, Dodd G. Is there an effect of dysphonic teachers' voices on children's processing of spoken language? J Voice. 2005;19(1):47-60.

18. Brasil. Ministério do Trabalho e Emprego - MTE. [Internet]. [citado 2008 Ago 20]. Disponível em http://www.mte.gov.br/legislacao/ normas_regulamentadoras/default.asp.

19. Jaroszewski GC, Zeigelboim BS, Lacerda A. Ruído escolar e sua implicação na atividade de ditado. Rev CEFAC. 2007;9(1):122-32

20. Dreossi RCF, Momensohn-Santos T. O ruído e sua interferência sobre estudantes em uma sala de aula: revisão de literatura. Pró-Fono. $2005 ; 17(2): 251-8$.

21. Lacerda A, Marasca C. Percepção auditiva de alunos e professores dos níveis de pressão sonora presentes nas escolas e suas implicações na prática escolar. Pró-Fono. 2002;14(1):85-92.

22. Cuenca R, Garzón EF, Kohen J, Garrido MP, Guzmán LR, Tomasina F. Condiciones de trabajo y salud docente. Estudios de casos en Argentina, Chile, Ecuador, Mexico, Peru y Uruguay. Santiago: Oficina Regional de Educación para América Latina y el Caribe; 2005. [citado em 3 de novembro de 2008] Disponível em: http://www.educarchile.cl/UserFiles/ P0001/File/condiciones_trabajo_salud_docente.pdf.

23. Martins RHG, Tavares ELM, Lima Neto AC, Fioravanti MP. Surdez ocupacional em professores: um diagnóstico provável. Rev Bras Otorrinolaringol. 2007;73(2):239-44.

24. ABNT NBR 10151/2000. Acústica - Avaliação do ruído em áreas habitadas, visando o conforto da comunidade - Procedimento [Internet]. [citado 2009 Mar 21]. Disponível em: http://www.abntcatalogo.com.br/ norma.aspx?ID=2206.

25. Ortiz E, Aves LEA, Costa E. Saúde vocal de professores da rede municipal de ensino de cidade do interior de São Paulo. Rev Bras Med Trabalho. 2004:2(4):263-6.

26. Smith E, Gray SD, Dove H, Kirchner L, Heras H. Frequency and effects of teachers' voice problems. J Voice. 1997;11(1):81-7.

27. Gasparini SM, Barreto SM, Assunção AV. O professor, as condições de trabalho e os efeitos sobre a saúde. Educ Pesqui. 2005;31(2):189-99.

28. Ferreira LP, Servilha EAM, Masson MLV, Reinaldi MBFM. Políticas públicas e voz do professor: caracterização das leis brasileiras. Rev Soc Bras Fonoaudiol. 2009;14(1):1-7

29. Carlloto MS. A síndrome de Burnout e o trabalho docente. Psicol Estud. 2002;7(1):21-9. 